\title{
O CYBORG E A ESCRAVA: GEOGRAFIAS DA MORTE E IMAGINAÇÃO POLÍTICA NA DIÁSPORA NEGRA
}

\author{
João da Costa Vargas ${ }^{1}$
}

Resumo: A fim de explorar maneiras pelas quais podemos abordar o ódio antinegro, um fundamento da sociabilidade moderna, analiso neste artigo dois tipos ideais da experiência política diaspórica e transtemporal negra: o cyborg e a escrava. Esses tipos ideais constituem referências analíticas com as quais podemos interpretar os mundos negros da vida e da morte: suas geografias, seus projetos políticos, e seus horizontes de desejos. Enquanto o cyborg recusa a abjeção das pessoas negras e luta para melhorar o mundo social, a escrava considera esse mundo fundamental e irremediavelmente antinegro, e, portanto, busca a fuga e o refúgio. O cyborg luta incansavelmente contra o racismo e enxerga (e tem esperanças de) um mundo social redimido no qual as pessoas negras fazem parte dele inquestionavelmente. Com o seu bloco politico multirracial, o cyborg demanda a reforma da sociedade; ele acredita na promessa da democracia multirracial. A escrava luta contra a antinegritude, e, portanto, quer a destruição do mundo e de seus protocolos de sociabilidade e ontologia.

Palavras-chave: racismo e antinegritude; o cyborg negro e a escrava; ideologia e utopia.

\section{THE CYBORG AND THE SLAVE: GEOGRAPHIES OF DEATH AND POLITICAL IMAGINATION IN THE BLACK DIASPORA}

\begin{abstract}
In order to explore ways in which we can address anti-black hatred, a foundation of modern sociability, in this article I analyze two ideal types of black diasporic and transtemporal political experience: the cyborg and the slave. These ideal types are analytical references with which we can interpret the black worlds of life and death: their geographies, their political projects, and their horizons of desires. While the cyborg refuses the abjection of black people and struggles to improve the social world, the slave considers this world fundamentally and hopelessly anti-black, and therefore seeks escape and refuge. The cyborg fights tirelessly against racism and sees (and hopes for) a redeemed social world in which black people are unquestionably part of it. With its multiracial political
\end{abstract}

\footnotetext{
${ }^{1}$ Professor da Universidade Riverside, EUA. Autor de Never Meant to Survive: Genocide and Utopias in Black Diaspora Communities. ORCID: https://orcid.org/0000-0002-1335-0179 ; E-mail: costavargas@gmail.com
} 
bloc, the cyborg demands the reform of society; he believes in the promise of multiracial democracy. The slave fights against anti-blackness, and therefore wants the destruction of the world and its protocols of sociability and ontology.

Keywords: racism and anti-blackness; the black cyborg and the slave; ideology and utopia.

\section{EL CYBORG Y EL ESCLAVO: GEOGRAFÍAS DE LA MUERTE E IMAGINACIÓN POLÍTICA EN LA DIÁSPORA NEGRA}

Resumen: Con el fin de explorar formas en las que podemos abordar el odio anti-negro, una base de la sociabilidad moderna, en este artículo analizo dos tipos ideales de experiencia política diaspórica y trans-temporal negra: el cyborg y el esclavo. Estos tipos ideales son referencias analíticas con las que podemos interpretar los mundos negros de la vida y la muerte: sus geografías, sus proyectos políticos y sus horizontes de deseos. Mientras el cyborg rechaza la abyección de los negros y lucha por mejorar el mundo social, el esclavo considera este mundo fundamental y desesperadamente anti-negro, y por lo tanto busca escape y refugio. El cyborg lucha incansablemente contra el racismo y ve (y espera) un mundo social redimido en el que los negros son, sin duda, parte de él. Con su bloque político multirracial, el cyborg exige la reforma de la sociedad; él cree en la promesa de una democracia multirracial. El esclavo lucha contra la anti-negrura, y por eso quiere la destrucción del mundo y sus protocolos de sociabilidad y ontología.

Keywords: racismo y anti-negritud; el cyborg negro y el esclavo; ideología y utopía.

\section{LE CYBORG ET L'ESCLAVE: GÉOGRAPHIES DE LA MORT ET L'IMAGINATION POLITIQUE DANS LA DIASPORA NOIRE}

Résumé: Afin d'explorer les moyens de lutter contre la haine anti-noire, fondement de la sociabilité moderne, j'analyse dans cet article deux types idéaux d'expériences politiques diasporiques et trans-temporelles noires: le cyborg et l'esclave. Ces types idéaux sont des références analytiques avec lesquelles nous pouvons interpréter les mondes noirs de la vie et de la mort: leurs géographies, leurs projets politiques et leurs horizons de désirs. Alors que le cyborg refuse l'abjection des Noirs et lutte pour améliorer le monde social, l'esclave considère ce monde fondamentalement et désespérément anti-noir, et cherche donc à s'échapper et à se réfugier. Le cyborg lutte sans relâche contre le racisme et voit (et espère) un monde social racheté dans lequel les Noirs en font incontestablement partie. Avec son bloc politique multiracial, le cyborg réclame la réforme de la société; il croit en la promesse d'une démocratie multiraciale. L'esclave lutte contre l'anti-noirceur, et veut donc la destruction du monde et de ses protocoles de sociabilité et d'ontologie.

Mots clés: racisme et anti-noirceur; le cyborg noir et l'esclave; idéologie et utopie.

Este ensaio propõe uma reflexão sobre aspectos da imaginação política na diáspora negra. Mais especificamente, ele apresenta uma análise crítica de uma colaboração 
transnacional negra iniciada há 25 anos atrás entre ativistas negras e negros do Brasil e dos Estados Unidos (VARGAS, 2018). O foco nessa colaboração, que de várias maneiras persiste na forma de programas e relações institucionais e pessoais em curso, nos ajuda a entender os desafios contemporâneos na conceitualização e combate ao genocídio antinegro. Um fenômeno definidor da diáspora negra, inscrito de maneira fundamental nos espaços geográficos, sociais, biológicos, cognitivos, e imaginativos, o genocídio antinegro requer um arcabouço teórico distinto das perspectivas teóricas canônicas que analisam o racismo e apontam caminhos de reforma e de salvação do projeto da democracia racial transcontinental.

Ao utilizar o termo "fundamental", friso algo que análises comuns do racismo frequentemente ignoram: a permanência, ubiquidade, e centralidade do ódio antinegro na constituição e dinâmica contemporânea das sociedades estruturadas de acordo com os princípios jurídicos e ontológicos da modernidade. Ou seja, diferentemente do racismo, o qual é tratado por análises críticas e progressistas como um defeito social que pode ser ajustado ou mesmo eliminado, a antinegritude, um conceito completamente diferente do racismo, sugere que o ódio à pessoa negra é um dado permanente e fundante da república moderna e suas ontologias constituintes.

A fim de explorar maneiras pelas quais podemos abordar esse ódio antinegro fundante, analiso abaixo dois tipos ideais da experiência política diaspórica e transtemporal negra: o cyborg e a escrava. Como tipos ideais, eles não correspondem ao que ocorre no mundo social, no qual suas características aparecem frequentemente combinadas. Mas esses tipos ideais constituem referências analíticas com as quais podemos interpretar os mundos negros da vida e da morte: suas geografias, seus projetos políticos, e seus horizontes de desejos. A diferença fundamental entre esses dois tipos ideais é a seguinte: enquanto o cyborg recusa a abjeção das pessoas negras e luta para melhorar o mundo social, a escrava considera esse mundo fundamental e irremediavelmente antinegro, e, portanto, busca a fuga e o refúgio. O cyborg luta incansavelmente contra o racismo e enxerga (e tem esperanças de) um mundo social redimido no qual as pessoas negras fazem parte dele inquestionavelmente. Por exemplo, o cyborg e seu bloco político protestam contra o abuso policial e demandam a reforma da polícia. A escrava luta pela abolição da polícia. Porque 
ela considera a antinegritude um dos alicerces conceituais do mundo moderno, a escrava quer a destruição do mundo e de seus protocolos de sociabilidade e ontologia.

Tanto o cyborg quanto a escrava empregam o conceito que Abdias do Nascimento (1980) chamou de quilombismo. O quilombismo insiste no fato de que a presença negra no estado-império moderno (JUNG, 2015) constitui a sua reserva ética. A pessoa negra, de acordo com Nascimento (1980: 149) "longe de ser uma iniciante, ou forasteira, é o corpo e alma desse país”. Esse reconhecimento da presença negra no Brasil enquanto fundamental e transformativa, como veremos abaixo, é análoga à centralidade que James Baldwin atribui ao povo negro, o aspecto nevrálgico do projeto democrático dos Estados Unidos. Em sua multiplicidade de formatos, Nascimento (1980: 152) explica,

... essa rede de associações, irmandades, clubes, terreiros, tendas, foram e são Quilombos Legalizados pela sociedade dominante; do outro lado da lei há os Quilombos clandestinos e secretos. De qualquer maneira, o "legalizado" e o "ilegal" formam uma unidade, uma afirmação humana, étnica e cultural única, que ao mesmo tempo une uma prática de liberação e assume of comando de sua própria história. Esse complexo de fenômenos Africanos, the uma práxis Afro-Brasileira, eu denomino de Quilombismo (NASCIMENTO, 1980, p. 152). ${ }^{2}$

O cyborg, produto de expectativas coletivas e das formações políticas e sociais que acompanham tais expectativas, é super-humano, onisciente, capaz de instruir, resistir, perdoar, e amar infinitamente. O cyborg rejeita o racismo e se dedica, incansavelmente, a reformar o mundo que habitamos. Apesar de por vez se definir revolucionário, o cyborg pensa e age de acordo com protocolos legais. Mesmo que talvez relutantemente, o cyborg segue o processo político normativo, e frequentemente opera à frente de blocos políticos multirraciais. Ao se empenharem na construção de uma república calibrada de acordo com ideais nobres de inclusão, esses blocos projetam um mundo social diverso e justo, que reconhece os erros do passado, e vê no futuro a esperança de melhoras.

Os blocos multirraciais que se aglutinam ao redor do cyborg demonstram ultraje moral com relação às formas múltiplas de sofrimento negro. Mas ao mesmo tempo, dado as exigências de comunalidade da multirracialidade, tais blocos desabilitam o entendimento dos aspectos estruturais e fundamentais da antinegritude. Tais exigências decorrem do fato

\footnotetext{
${ }^{2}$ Todas as traduções são do autor.
} 
de que, para se tornarem mutuamente legíveis, as experiências racializadas, de gênero, de sexualidade, e de classe social, entre outras, têm de operar de acordo com uma gramática comum de opressão. Entre os blocos multirraciais progressistas no Brasil, essa gramática é ilustrada no refrão utilizado em protestos que demandam justiça para "pessoas pobres, negras, e moradoras de periferias" (ALVES, 2011; VARGAS 2018: 206). Essa gramática parte do princípio que o racismo antinegro (algo muito distinto da antinegritude) é uma entre várias formas de opressão. O resultado desse princípio é que os aspectos singulares, irredutíveis, e fundantes da antinegritude são diluídos no universo de opressões comuns e comunicáveis enquanto tal. O abuso policial, por exemplo, ao invés de ser visto como um fenômeno que indiscutível e desproporcionalmente atinge pessoas negras, é tomado como um índice das injustiças que assolam as "pessoas pobres, negras, e moradoras de periferias”. Pode-se argumentar que esse refrão de inclusão serve para aglutinar as vítimas de injustiças que não se consideram negras - um dos desafios perenes dos movimentos negros no Brasil. Mas o efeito dessa inclusão é devastador: perde-se a centralidade da antinegritude como princípio fundamental da organização social do Brasil e, de fato, da modernidade. Ao contrário do racismo, a antinegritude é um dado permanente e irremovível da sociedade: a antinegritude não só define estruturas sociais de privilégios (para pessoas não negras) e desvantagens (para pessoas negras), mas também estabelece a família humana como sendo composta por pessoas não negras, fundamentalmente excluindo as pessoas negras de seu âmbito (VARGAS, 2020). Ser, na família humana, significa não ser negro.

Mas o cyborg nunca desiste desse mundo. Enraizado nas comunidades quilombolas transcendentais e fugitivas, o cyborg se alimenta do acúmulo de saberes e estratégias transgeracionais. O cyborg é parte de um esforço coletivo histórico e contemporâneo que gera uma energia política que acredita no futuro. Tanto na vida quanto na morte, o cyborg incansavelmente luta pela redenção do projeto democrático de inclusão multirracial. Isso muitas vezes ocorre mesmo depois da morte física do cyborg. Os casos recentes de Amarildo de Souza, Cláudia Ferreira, e Marielle Franco, entre outras vítimas fatais da antinegritude do estado-império, mostram que o poder de galvanização política multirracial do cyborg às vezes se estende e até se amplia postumamente. $\mathrm{O}$ cyborg, afinal, encarna o 
projeto coletivo negro de uma sociedade nova, "fundada na justiça, igualdade e respeito por todos seres humanos; na liberdade; uma sociedade cuja natureza intrínseca torna impossível a exploração econômica ou racial. Uma democracia autêntica, fundada pelos destituídos e deserdados do país" (NASCIMENTO, 1980: 160).

Apesar de Nascimento reconhecer a centralidade das mulheres negras na constituição e atualização dos ideais do quilombo, é preciso estender sua análise no que tange tanto o poder simbólico desse projeto coletivo quanto a sua constituição interna. Uma construção análoga ao quilombo pode ser apreendida na teorização de Joy James (1999: 38) sobre a comunidade transcendente,

que se estende através do tempo e do espaço...; assim, sua "transcendência" inclui os antepassados bem como a coletividade presente e as crianças futuras ainda não nascidas. Todos são parte da "comunidade". O conteúdo e a qualidade das relações comunais provêm da prática. (Consequentemente, a habilidade que se tem de considerar a comunidade algo que inclui aqueles que não vivem no mundo "livre" se torna um teste para os limites da transcendência.) Aqui, relações são determinantes e moldam a busca e construção da comunidade transcendente. Aqui, o coletivo se sobrepõe ao individualismo. Apesar de ser articulados por indivíduos, conhecimento e sabedoria são adquiridos através de esforço coletivo. Quando o conhecimento é a "experiência da realidade mais profunda encontrada entre os antepassados espirituais e os pensadores que estão fisicamente vivos", ele só pode se desenvolver em relação, em uma comunidade transcendente (JAMES, 1999, p. 38 ).

Essa comunidade transcendente, ou o quilombo, por ser imaginada e vivenciada em exílio (mesmo que, como veremos abaixo, o cyborg de James Baldwin, paradigmático na diáspora, insiste que "esse é nosso país"), em movimento, na imaginação, e na esperança, é também uma comunidade fugitiva. Essa comunidade fugitiva, como afirma Jurema Werneck (2007: 102), é fruto das formas alternativas de sociabilidade, habitação, e estratégias políticas que as pessoas escravizadas elaboraram, tanto para voltar a África (de fato ou imaginativamente) quanto para inventarem novas geografias. "Novas alternativas tiveram de ser recriadas e aplicadas", continua Werneck (2007: 102), "no sentido de buscar novos patamares de existência cultural e resistência. Ao mesmo tempo, padrões antigos e tradições tiveram de ser recriadas e adaptadas a essas condições adversas, tanto na África quanto nesses novos territórios”. É a centralidade fundamental das mulheres negras ao 
longo das gerações de comunidades quilombolas transcendentes fugitivas que revelam as culturas arkhé. Essas culturas "privilegiam noções de tempo cíclicas e maneiras particulares de rituais que infiltram o Ocidente e sua racionalidade, combinando-se com essa racionalidade ao mesmo tempo que almeja enfraquece-la" (WERNECK, 2007: 100).

A figura da Ialodê simboliza a prática cultural e política de mulheres negras que precedem o período da escravidão ao mesmo tempo em que se mantém no presente através de tradições orais e corporais. No caso do Brasil, de acordo com Werneck, as Ialodês (2007: 104),

podem ser vistas em comunidades negras onde mulheres, assumindo liderança ou papéis de responsabilidade coletivos, desenvolvem ações nas quais um futuro é afirmado para todos aqueles subordinados a elas. Isso ocorre nas lutas para melhorar as condições materiais do povo e no desenvolvimento de comportamentos e atividades que almejam recuperar a pertinência e relevância contemporânea de uma perspectiva imaterial. Assim, as Ialodês ganham importância e são celebradas não somente nas comunidades religiosas Afro-Brasileiras, nas quais elas têm um papel fundamental de disseminar o axé, mas também fora desses espaços sagrados (WERNECK, 2007, p. 104).

A comunidade fugitiva do cyborg, portanto, é a comunidade alicerçada na figura da Ialodê, a comunidade fugitiva na qual mulheres negras são o seu centro criativo, político, e de ação. Essa comunidade, apesar de ser rejeitada e temida pela sociedade, não rejeita a noção da república multirracial. Ao contrário: o cyborg, dependente das Ialodês, e, portanto, um produto de um mundo social transhistórico e transcontinental negro, modula seus pensamentos e ações de acordo com um diagrama que prefigura a redenção de toda a república. $\mathrm{O}$ amor infinito, paciente, sapiente, e ao mesmo tempo insistente do cyborg negro e de sua cultura arkhé geram uma referência a partir da qual a comunidade expandida e multirracial deve ser estabelecida. A história da salvação implica a construção dessa comunidade expandida de acordo com os princípios estruturantes dos quilombos. Apesar de o cyborg não viver no mundo livre, e ser, como ser negro, constantemente rejeitado, ele sabe o que é liberdade: o quilombo transcendental e fugitivo das Ialodês constitui o reservatório conceitual e moral segundo o qual uma liberdade expandida, que realiza o potencial da república democrática multirracial, pode ser imaginada e colocada e prática. 
Em um ensaio de 1983, “A Cyborg Manifesto", Donna Haraway desenvolve o conceito de um cyborg feminista como "um organismo cibernético, um híbrido de máquina e organismo, uma criatura da realidade social bem como uma criatura de ficção". O projeto de Haraway (1991: 149-50)

é um esforço de contribuir para uma cultura e teoria feminista-socialista de um modo pos-modernista e na tradição utópica de imaginar um mundo sem gênero, quer dizer, talvez, um mundo sem gênese, e talvez também um mundo sem fim. A encarnação do cyborg está fora da história de salvação (salvation history.) E não marca o tempo em um calendário édipo, na tentativa de curar as mazelas terríveis causadas pelo gênero através de uma utopia simbiótica oral ou de um apocalipse edipiano (HARAWAY, 1991, p. 149-50).

O nosso cyborg negro, fruto dos quilombos das Ialodês, não está imaginando explicitamente um mundo sem gênero, apesar de possuir a experiência social de ser constantemente extirpado do gênero: ao mesmo tempo excedendo as categorias do gênero e nunca as atualizando, mas sempre expulso de seu universo de expectativas e práticas normativas (SPILLERS, 2003). O ser do cyborg negro é o ser para quem o Humano e suas correspondências de gênero são impossíveis. O objeto de violência simbólica e violência concreta constante, incluindo as violências sancionadas pelo estado-império, e sendo objeto de imagens controladoras (controlling images, COLLINS, 1990), o cyborg inevitavelmente funde todos os genêros, e, portanto, apaga todos os gêneros. A pessoa negra, escreve Patrice Douglass (2018: 115), "pode ser tudo e nada simultaneamente. A negritude adquire gênero através da violência, a qual estrutura o gênero negro fora da humanidade e assim define o perímetro do que significa ser para o Humano e suas antíteses”. O cyborg negro, seja ele categorizado como homem, mulher, ou não-binário, é desde sempre sujeito a formas específicas de violência simbólica e factual. Em outras palavras, "quando o gênero e a negritude convergem, as pessoas negras se encontram a esmo em um oceano de violência" (DOUGLASS, 2018: 116). O cyborg negro, e a antinegritude mais abrangentemente, nos fazem perguntar em que medida o gênero, como uma categoria analítica, é relevante num mundo social marcado por violência gratuita e permanente. É precisamente essa iminência e ubiquidade da violência que nos faz refletir sobre o gênero a partir da antinegritude. Ou, mais precisamente, nos faz refletir sobre as maneiras pelas 
quais a antinegritude marca a expulsão das pessoas negras da simbologia normativa do gênero (SNORTON, 2017: 105) e do humano.

Fora, portanto, do Humano e de sua socialidade, e fora do gênero, o cyborg negro está dentro da história da salvação. Ele recusa as expulsões múltiplas que esse mundo lhe impõe; ele está resolvido a consertar o projeto ideológico da democracia multirracial. Diferentemente da figura da escrava, a qual encontraremos mais tarde, o cyborg negro e sua comunidade fugitiva estão investidos em uma teleologia. Essa teleologia, que concebe o sofrimento atual como um estágio necessário rumo a um mundo reformado, traz nela um método político. Apontado um caminho que vai da crise estrutural e permanente - o etos nacional suicida que se alimenta do ódio às pessoas negras, e requer sua morte - a uma república redimida e liberada, esse método político deriva dos princípios de reconhecimento mútuo e racionalidade comunicativa. "Será difícil", James Baldwin nos lembra, mas para o cyborg não há outro caminho. O cyborg negro e sua comunidade fugitiva são toda a esperança de sobrevivência dessa república presentemente capenga, mas arquitetonicamente sólida.

Em “My Dungeon Shook”, (“Minha Masmorra Tremeu”), um ensaio dedicado ao seu sobrinho no centésimo aniversário da emancipação dos escravizados nos Estados Unidos, Baldwin (1998: 294) delineou os aspectos mais importantes do cyborg negro. Refletindo sobre o papel político-pedagógico que as pessoas negras têm de aceitar a fim de salvar o projeto democrático multirracial, para Baldwin era essencial que

Nós [pessoas negras], com amor... forcem nossos irmãos [negros e não-negros] a se verem com eles são, que parem de fugir da realidade e comecem a muda-la. Pois esse é nosso pais, meu amigo, não o abandone; homens grandes fizeram grandes obras aqui, e o farão novamente, e nós podemos transformar a América naquilo que a América deve ser. Será difícil, James, mas você vem de uma linhagem forte de agricultores, homens que colheram algodão e construíram represas e ferrovias, e, contrariando todas as mais terríveis circunstâncias, alcançaram uma dignidade inatacável e monumental (BALDWIN, 1998, p. 294).

Na visão de mundo de Baldwin, a redenção do estado-império depende inegável e fundamentalmente das pessoas negras, cuja missão é de reestabelecer o centro moral e vocação histórica da polis. A despeito do ódio desumanizador voltado a elas, as pessoas 
negras são incumbidas de educar, direcionar, e redimir brancos e não-negros com amor e insistência. "Será difícil", alertara Baldwin, mas as pessoas negras vêm de uma linhagem extraordinária: as qualidades super-humanas do cyborg permitirão a superação de todos os obstáculos. Não há outra esperança para o projeto democrático dos Estados Unidos, corrompido profundamente por uma disposição antinegra suicida. Suicida porque, se o desejo genocida fosse completamente bem-sucedido, ele extinguiria os únicos atores políticos capazes de restaurar a república e a sua teleologia que aponta para uma multirracialidade harmoniosa. O sujeito político ideal de Baldwin é um cyborg porque, apesar de seu saber e força acumulados ao longo de gerações, ele sabe que o processo e encarnação da redenção significam habitar o não-lugar do sofrimento e mesmo da morte. Um compromisso, força, e amor super-humano, necessários para abordar e mudar aqueles que o odeiam: esses são precisamente os elementos centrais da constituição do cyborg. Sem o cyborg negro, não há a possibilidade da democracia racial, não há processo que transforma a "América naquilo que a América deve ser".

"Não será fácil”, mas o cyborg negro e sua comunidade fugitiva não têm outra escolha a não ser encarnar, plenamente, a tarefa primordial de redimir o projeto democrático. Baldwin (1998: 293-4), elabora: "Você", querendo dizer, vocês pessoas negras dos quilombos das Ialodês, "têm de os aceitar", querendo dizer, os brancos e não negros, "com amor. Porque essas pessoas inocentes não têm outra esperança. Elas ainda estão presas a uma história que elas não entendem; e enquanto elas não a entenderem, elas não poderão ser libertadas dessa história”. As pessoas não negras - as brancas em particular - têm de ser instruídas, direcionadas, edificadas: são elas que precisam de ser liberadas. Aquelas pessoas possuídas pelo ódio antinegro são as que, afinal, carecem mais de compaixão, ajuda e amor.

O método do cyborg negro - ou seja, o método de Baldwin de redenção social implica em aceitar a luta política, a qual é elaborada e iniciada no quilombo transcendental das Ialodês. Segundo esse método, o comprometimento ético do cyborg e seu apelo moral levarão ao reestabelecimento da república multirracial democrática. Tal comprometimento requer um processo longo de educar aqueles que não entendem a relevância do momento histórico - tanto seus precedentes quanto suas promessas - e são, portanto, incapazes de 
desvencilharem-se da antinegritude. Trata-se de um fardo pesado, multifacetado, quase impossível de ser levado adiante. O cyborg negro e seu quilombo transcendental fugitivo têm de projetar e atualizar o método da redenção; eles têm de aceitar e amar incondicionalmente aqueles que os odeiam; eles têm de os informar e educar; eles têm de suprimir sua própria revolta ao mesmo tempo em que se dedicam à pedagogia que trará liberdade àqueles presos na sua própria ignorância e ódio. O cyborg negro é o reservatório moral máximo, a esperança profética, e o liberador do estado-império multirracial.

O cyborg negro de Baldwin evidencia paralelos com a teoria do Black Power, ou Poder Negro. Em Black Power (1967), de Kwame Ture e Charles Hamilton, o conceito de Poder Negro é apresentado como "uma chamada ao povo negro nesse país para unirem-se, reconhecerem a sua herança, e construírem um sentido de comunidade. É uma chamada para que as pessoas negras comecem a definir seus objetivos próprios, liderar suas organizações próprias, e as apoiar. É uma chamada para rejeitar as instituições e valores racistas desta sociedade" (44). Apesar de o papel das pessoas negras na restauração da sociedade democrática não constar em Black Power tão centralmente quanto em "Minha Masmorra Tremeu", o argumento de Ture e Hamilton sugere que o processo dialógico rigoroso e aberto constitui o método através do qual "o racismo institucional” - o qual “depende na atualização generalizada de atitudes e práticas anti-negras" (5) - é identificado, combatido e eliminado. Esse raciocínio implica a noção de autonomia dialógica: "Antes que um grupo possa entrar a sociedade aberta, ele tem de se consolidar internamente. Isso quer dizer que a solidariedade interna é necessária antes que um grupo possa operar efetivamente, de uma posição de negociação forte, dentro de uma sociedade pluralista" (44).

$\mathrm{O}$ aspecto da autonomia nessa análise é evidente: o bloco negro tem de "consolidar internamente": ele tem de se reconhecer enquanto tal, empregar o seu próprio conhecimento, acumulado ao longo de gerações, e somente depois disso engajar a sociedade mais ampla. Esse último aspecto do Poder Negro - o engajamento com atores políticos e instituições não negros - constitui o seu componente dialógico. De maneira similar à missão do cyborg de Baldwin, o Poder Negro almeja engajar e consertar as práticas políticas e os protocolos institucionais. Através da autonomia dialógica, o cyborg 
do Poder Negro transforma o seu quilombo fugitivo no reservatório moral e político da república, do qual a republica necessita desesperadamente para a sua sobrevivência e reforma. Ademais, esse cyborg anuncia também que uma batalha maior, para além das fronteiras do quilombo transcendental, é necessária. Para que o projeto imperial-nacional de reconstrução seja bem-sucedido, ele tem de abraçar plenamente a arena política multirracial e a sociedade civil. Está implicado, aqui, que uma vez nessa arena expandida, num processo semelhante à batalha contra-hegemônica de posições, e através de diálogos e tentativas de alianças difíceis, o desafio maior é estabelecer denominadores comuns de experiências entre pessoas negras e não negras.

Talvez porque eles anteciparam o perigo da orientação dialógica, Ture e Hamilton concluíram Black Power enfatizando a irredutibilidade das experiências negras. Essas experiências singulares de exclusão, os autores insistem, geram ângulos críticos únicos. O quilombo transcendente do qual o Poder Negro emerge é marcado por um privilégio epistêmico que pode salvar a democracia multirracial. "Nesse país", Ture e Hamilton explicam, "nós antecipamos que o povo negro oprimido é o grupo mais legítimo e o mais provável de testar o sistema e de levantar as perguntas mais difíceis. O professor Kenneth Clarke escreveu '... o Negro na América, por causa dos padrões intensos de rejeição racial... foi forçado a um grau de alienação e separação que resultaram em um padrão de consequências sociais e de personalidade. Algumas dessas consequências foram uma perspectiva e sensibilidade aguçadas acerca das forças sutis que são significantes na nossa estrutura social complexa"” (180).

A autonomia dialógica orienta o cyborg negro. O cyborg do Black Power procura uma comunidade transcendental que é inclusiva: pessoas negras e não negras coabitam sob os mesmos princípios de sociabilidade, e pessoas negras e não negras operam ontológica e socialmente sob os mesmos princípios de uma humanidade inquestionável. O perigo que talvez Ture e Hamilton perceberam foi que, ao enfatizarem a tradutibilidade multirracial, a especificidade das experiências negras poderia ser empurrada para as margens e eventualmente negada. O problema político criado aqui é considerável, um problema que é muito presente: apesar de a opressão das pessoas negras ser a base das mobilizações multirraciais - por exemplo, os esforços diaspóricos de protestar contra o uso da força letal 
pela polícia (VARGAS, 2018: 181-210) - dado o imperativo da tradutibilidade multirracial, essa opressão é comumente apresentada como sendo análoga à opressão sofrida por não negros. "O abuso policial afeta todos": ao se pronunciarem dessa maneira, mobilizações multirraciais agem como se as pessoas negas e suas comunidades não fossem, ontológica e fundamentalmente, consideradas não humanas, e, portanto, os alvos categóricos de discriminação institucional e do emprego de força letal pelo estado e outros atores sociais.

As orientações do Poder Negro do cyborg aguçam a facilidade normativa com que formações políticas da diáspora, mesmo as lideradas por pessoas negras, vão de um ultraje moral ancorado no reconhecimento de como o estado-império sanciona a morte extralegal de pessoas negras, a uma asserção de uma comunalidade experiencial multirracial. Esse imperativo de tradutibilidade multirracial, no entanto, é precisamente o sine qua non dos blocos políticos multirraciais - mesmo, e especialmente, aqueles liderados por pessoas negras. O cyborg negro orientado pelo Black Power, afinal, é o guardião das leis da pátria, e quer reformar o projeto imperial-nacional de tal modo que o seu espírito de inclusão seja aplicável a todos e reconhecido por todos. Ture foi bem explícito com relação às orientações reformistas do Poder Negro. Em um posfácio de 1992, ele afirmou que o Poder Negro “... prega reforma”, e que "todas as ações propostas nesse livro são legais" (187, 188). Combinado com seu ethos anticapitalista, o Poder Negro insiste em ações políticas dentro da lei. O objetivo, como o do quilombismo (NASCIMENTO, 1980: 162), consiste em capturar poder através de organizações negras locais e do estabelecimento de alianças políticas multirraciais cuidadosamente avaliadas. O cyborg negro aborda o estado-império como se ele fosse poroso às demandas negras e à presença negra. A república pode ser resgatada. O bloco político multirracial liderado pelo cyborg negro reformista, apesar de ultrajado por mais um caso de morte negra evitável, acredita no aperfeiçoamento da república atualmente corrompida. O cyborg do Poder Negro é fundamentalmente otimista e segue um cronoscópio que registra a passagem do tempo através de melhoras sociais.

O cyborg negro é um experimento social. Como o quilombo transcendental e fugitivo das Ialodês, o cyborg negro se encontra "em um processo constante de revitalização e remodernização, respondendo às necessidades dos tempos históricos variados e do contexto geográfico" (NASCIMENTO, 1980: 153). O cyborg tenta salvar o 
mundo constituído através de sua exploração do que é ser humano: imaginando, habitando, se transformando, e divergindo do Humano. Uma figura liminal, o resultado de uma ficção social, eminentemente eficaz na criação da coerência que estrutura blocos políticos multirraciais que almejam a inclusão social definitiva, o cyborg falha em manter a antinegritude no centro de sua gramática política. Tal falha é intencional, ou ao menos é uma necessidade. Para ser efetivo na coesão do seu bloco multirracial, o cyborg tem de afirmar as comunalidade das opressões (de raça, classe social, gênero, e sexualidade, entre outras) ao mesmo tempo em que não pode, sob risco de ser acusado de enfatizar particularismos negros destrutivos, apontar para os códigos antinegro que estruturam a república e suas sociabilidades e ontologias.

Refletir sobre a figura da escrava significa engajar um outro gênero negro do humano. Ao passo que o cyborg das Ialodês e dos quilombos transcendentais fugitivos quer mudanças dentro da legalidade, a escrava não está preocupada com a legalidade, e abraça possibilidades de transformação por qualquer via necessária. Ao passo que ambos o cyborg e a escrava emergem de quilombos transcendentais, a escrava não tem interesse em diluir as aspirações, singularidades, e visões de mundo negros no conjunto político multirracial mais amplo. A distinção entre ideologia e utopia pode ser útil no esforço de diferenciar os modos de ação política do cyborg e da escrava. Aqui está a distinção conceitual de Dolores Hayden (1976: 349):

... eu tenho usado o termo "utopia" para me referir a um esquema imaginário ou experimental de uma sociedade ideal, e eu tenho usado "ideologia" para me referir a um corpo de idéias no qual se baseia um sistema político, econômico, ou social particular, real ou ideal. Em uma discussão extensiva sobre a mentalidade utópica, Karl Mannheim define esses termos mais estreitamente. Para ele, tanto a utopia quanto a ideologia são ideias ou valores que transcendem a ordem existente, mas ele limita "utopias" às ideias que oferecem possibilidades revolucionárias, enquanto "ideologias" harmonizam com o espírito de uma era de modo esperançoso, mas não revolucionário. Observadores que consciente ou inconscientemente resistem mudanças revolucionárias irão minimizar a distinção entre utopias e ideologias, e as verão igualmente irrealizáveis. Mas aqueles que procuram mudanças precisam reconhecer e explorar as utopias como "o material explosivo que arrebentará os limites da ordem existente", e que contém "de forma condensada as tendências não realizadas que representam as necessidades de cada era (HAYDEN, 1976, p. 349).

Revista da ABPN • v. 12, n. $34 \cdot$ Set - Nov 2020, p.54-72 
O cyborg do Black Power opera de acordo com a ideologia, ao passo que a escrava se pauta por uma noção de utopia. A figura da escrava quer arrebentar os limites da ordem existente. A escrava não pode se comprometer com a lei e os arranjos institucionais vigentes. Para a escrava, utopia, e não ideologia, é o imperativo: o quilombo fugitivo não é somente pautado na fuga, mas, fundamentalmente, na recusa de repousar, estacionar, de aceitar a ordem normativa. Abraçando movimento e transfiguração, a escrava imagina, ocupa, e deseja o espaço do fantástico. A escrava é a Ialodê fantástica. O fantástico é a utopia. Em um evento na biblioteca da Southern California (Southern California Library), em Los Angeles, em 2012, Cedric Robinson, autor do livro fundamental Black Marxism: The Making of the Black Radical Tradition (1983), descreveu sua cidade natal, Oakland, como o "espaço do fantástico". Black Marxism documenta minuciosamente as revoltas das pessoas escravizadas por toda a diáspora desde a inauguração da escravidão transaltântica, e sugere que o que movia essas pessoas era menos um impulso individual e mais a totalidade ontológica, que enfatiza as estruturas da mente coletiva, a propriedade comum, a metafísica - um mundo nunca redutível à logica da modernidade, do individualismo jurídico e social, e do capitalismo. A escrava está à procura de um genêro de humano distinto, o qual habita, requer, e, inevitavelmente, encarna o fantástico.

“Como um escravo", George Jackson (1990: 7) afirmou, “o fenômeno social que ocupa o todo da minha consciência é, obviamente, a revolução”. Diferentemente do cyborg, o escravo não utiliza nem engaja a lei, nem mesmo estrategicamente, porque ele reconhece na lei os princípios básicos da antinegritude. Afinal, "a tabula rasa da branquitude - que todos os grupos exceto as pessoas negras podem acessar - serve como pré-requisito da transubstanciação mágica da lei em um objeto a ser possuído em um sujeito proprietário" (into a thing to be possesssed into a property-owning subject) (WEHELIYE, 2014: 78). A revolução, na sua modalidade fantástica-utópica, informada pelo quilombo fugitivo das Ialodês, é a destruição dos códigos que fazem a humanidade impossível para as pessoas negras. "No fim", estabelece Weheliye (2014: 79), "a lei, quer restrita a fronteiras nacionais ou globais, estabelece uma divisão internacional da humanidade, a qual outorga a sujeitos previamente excluídos acesso limitado ao conceito de pessoa como propriedade, ao mesmo tempo em que fortalece a supremacia do Homem". 
A escrava rompe com a história da salvação ao estabelecer o que Fanon (1967: 229) chama do "salto real", o qual "consiste em introduzir invenção à existência". Como sugeriu Marriott (2014: 518), a invenção não é parte de uma teleologia, ou da história da salvação. Ao contrário, trata-se de uma metáfora para um tipo de a-temporalidade fora da hora ("untimeliness"), "que implica um salto, e esse salto não pode ser antecipado, não se pode preparar para ele, e ele não pode ser retraçado a um período histórico anterior... A invenção, porque é transformação radical, não é redutível à economia ou à estratégia, e, portanto, talvez queiramos dizer, não é mais uma forma de cálculo político". E mesmo que Marriott não relacione invenção à utopia, é precisamente a sua imprevisibilidade, e a sua rejeição da história como uma narrativa de progressão, que torna a invenção, da perspectiva do quilombo transcendental das Ialodês, a ferramenta e substância da utopia, "o material explosivo" que arrebenta não somente a ordem existente, mas também a dependência dessa ordem na história da salvação. A utopia, para a escrava, não é definida, não é uma idealização, não é perfectibilidade. Ao contrário, a utopia é a realização do impossível, ou a impossibilidade da realização. É somente nessa liminalidade, quando a invenção reconfigura a existência (e, portanto, destrói o que entendemos por ela), nessa terra e tempo de ninguém, que a escrava pode se des-tornar escrava, e se tornar o não se tornar da história da salvação. É assim que eu leio a descrição de George Jackson (1990: 7) da morte social, que é também uma maneira de conceitualizar essa terra e tempo de ninguém:

Nascido para morrer prematuramente, para ser um trabalhador manual ganhando um salário de subsistência, o quebra-galho, o limpador, o preso... - esse sou eu, a vítima colonial. Qualquer um que passar o exame do serviço social hoje pode me matar amanhã. Qualquer um que passou o exame do serviço social ontem pode me matar hoje com impunidade completa. Eu vivi com repressão todo momento da minha vida, uma repressão tão formidável que qualquer movimento de minha parte só pode trazer alívio, uma satisfação de uma vitória pequena, ou a liberdade da morte. Em todo sentido da palavra, em todo sentido que é real, eu sou escravo da propriedade, sou escravo pela propriedade (I'm a slave to, and of, property) (JACKSON, 1990, p. 7).

O mapa mais amplo de possibilidades conceituais sugerido nessa passagem, derivado do reconhecimento que a letalidade antinegra codifica todas as instituições e sociabilidades do estado-império, abre mundos opostos aos mundos da legalidade, mundos 
para além da legalidade. Ao impactar toda existência hegemônica através da invenção utópica, a escrava do quilombo transcendental quer "abolir o chão sobre o qual todas as formas de subjugação são administradas" (WEHELIYE, 2015: 82). Aqui o conceito de abolição estabelece um contraste agudo com relação à redenção, à reforma, e às crenças e protocolos da história da salvação. Ao passo que o cyborg opera no intuito de eliminar o racismo - considerado um defeito social que será necessariamente remediado pelos esforços oriundos dos quilombos transcendentais - a escrava reconhece que a antinegritude é um dado irremovível da formação social planetária. A escrava só quer a destruição dessa formação global antinegra. Ao passo que o cyborg é o bricoleur que, com amor infinito, tentar rearranjar e consertar as partes defeituosas do projeto democrático multirracial, a escrava é a engenheira que deriva poder da rejeição da ordem desse mundo e abraça a busca incessante da invenção. Ao passo que o cyborg quer existir na polis reformada, a escrava rejeita a existência como a conhecemos: a escrava sabe que, como presentemente configurada, existir significa a não existência das pessoas negras. A escrava busca aquilo que vem depois do tempo do Homem. A escrava quer explodir a correspondência normativa entre o Humano e o Homem, uma correspondência, como aponta Sylvia Wynter (McKITTRICK, 2015), que permanentemente exclui as pessoas negras da Humanidade. Enquanto o cyborg rejeita o racismo e o considera um defeito reparável, a escrava rejeita a antinegritude e o mundo social como irreparáveis. A escrava quer um outro mundo, uma outra Humanidade.

\section{REFERÊNCIAS BIBLIOGRÁFICAS}

ALVES, Jaime Amparo. Necropolítica Racial: a Produção Espacial da Morte na cidade de São Paulo. Revista da Associação Brasileira de Pesquisadores/as negros/as (ABPN), v. 1, n.3, p.89-114, fev 2011. ISSN 2177-2770. Disponível em:M <https://abpnrevista.org.br/index.php/site/article/view/276>. Acesso em: 16 set. 2020.

BALDWIN, James. 1998. "My Dugeon Shook: Letter to My Nephew on the One Hundredth Anniversary of the Emancipation." Em James Baldwin: Collected Essays, edição: Toni Morrison. New York, NY: Library of America.

COLLINS, Patricia Hill. 1990. Black Feminist Thought: Knowledge, Consciousness, and the Politics of Empowerment. New York, NY: Routledge. 
DOUGLASS, Patrice. 2018. "Black Feminist Theory for the Dead and Dying." Theory \& Event 21 (1): 106-123.

FANON, Frantz. 1967. Black Skin, White Masks. Tradução: Charles Lam Markman. New York, NY: Grove Press.

HARAWAY, Donna. 1991. “A Cyborg Manifesto.” Em Simians, Cyborgs, and Women: The Reinvention of Nature, por Donna Haraway, 149-181. New York, NY : Routlege.

HAYDEN, Dolores. 1976. Seven American Utopias: The Architecture of Communitarian Socialism, 1790-1975. Cambridge, MA: The MIT Press.

JACKSON, George. 1990. Blood in my Eye. Baltimore: Black Classic Press.

JAMES, Joy. 1999. Shadowboxing: Representations of Black Feminist Politics. New York, NY: Palgrave.

JUNG, Moon-Kie. 2015. Beneath the Surface of White Supremacy: Denaturalizing U.S. Racisms Past and Present. Stanford, CA: Stanford University Press.

MARRIOTT, David. 2014. "No Lords A-Leaping: Fanon, C.L.R. James, and the Politics of Invention." Humanities 3: 517-545.

McKITTRICK, Katherine (ed.). 2015. Sylvia Wynter: On Being Human as Praxis. Durham, NC: Duke University Press.

NASCIMENTO, Abdias do. 1980. "Quilombismo: An Afro-Brazilian Political Alternative." Journal of Black Studies 11 (2): 141-178.

ROBINSON, Cedric. 2000. Black Marxism: The Making of the Black Radical Tradition. Chapel Hill, NC: The University of North Carolina Press.

SNORTON, C. Riley. 2017. Black on Both Sides: a Racial History of Trans Identity. Minneapolis, MN: Minnesota University Press.

SPILLERS, Hortense. 2003. Black, White, and in Color: Essays on American Literature and Culture. Chicago: The University of Chicago Press.

TURE, Kwame (Stokely Carmichael) and Charles Hamilton. 1967. Black Power: The Politics of Liberation in America. New York, NY : Knopf.

VARGAS, João H. C. 2020. "O Racismo Não dá conta: Antinegritude, a Dinâmica Ontológica e Social Definidora da Modernidade.” Revista em Pauta 45 (18): 16-26.

VARGAS, Joao H. C. 2018. The Denial of Antiblackness: Multiracial Redemption and Black Suffering. Minneapolis: University of Minnesota Press.

WEHELIYE, Alexander. 2014. Habeas Viscus: Racializing Assemblages, Biopolitics, and Black Feminist Theories of the Human. Durham, NC: Duke University Press. 


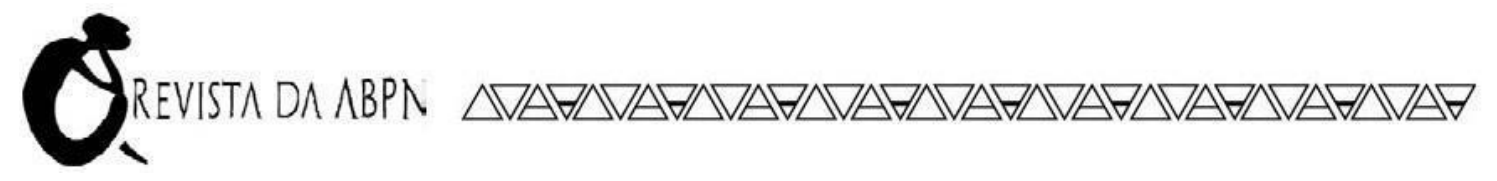

WERNECK, Jurema. 2007. “Of Ialodês and Feminists.” Cultural Dynamics 19 (1): 99-113.

Recebido em: 22/09/2020

Aceito em: 30/10/2020 